\title{
The George Fox University Freshman Experience: A Projects Based Integrative Approach to Engineering Design
}

\author{
John Natzke and Neal Ninteman \\ Math, Computer Science, and Engineering Department \\ George Fox University \\ Newberg, OR 97132
}

\begin{abstract}
In Fall 2000 a new engineering major with electrical and mechanical concentrations was initiated at George Fox University, and with it a new freshman experience entitled Engineering Principles I \& II. The two-course sequence provides an introduction to engineering problem solving and design for incoming freshmen, and covers the following topics: design methodologies, computer programming, engineering graphics, the visualization and modeling of real-world systems, and the history and ethics of the engineering profession. The course also equips the students in computer aided design tools, solid modeling and simulation software, and mathematics software applications. Though the subject matter is somewhat traditional, innovative ways have been introduced of structuring the class and engaging the first-year engineering students. The primary focus of the course is on five major team design projects during the year, in which the students utilize all of their gained knowledge and training, and apply the various engineering design methodologies and skills/tools. The design projects are presented in a variety of communication forms including written reports, oral presentations, and poster presentations. The course is structured to facilitate a highly hands-on active learning experience, with class meetings twice weekly in a lecture/lab setting for a total of three hours. In addition, both a machining skills component (six one-hour lab sessions in first semester) and an electronic instrument training component (six one-hour lab sessions in second semester) are being integrated into the course this year. The overall effectiveness and success of the course and the benefit to the George Fox engineering program and students will be presented and discussed.
\end{abstract}

\section{Introduction}

The first engineering students enrolled at George Fox University in 1987, in what was a 3/2 dualdegree engineering program. In this program, the students attended George Fox for three years working toward an applied science degree, and then transferred to a engineering degree granting institution to complete the final two years of course work towards a bachelors in engineering. Since the start of the program, the engineering students were required to take the introductory programming course offered by the computer science program. The need was seen, however, to identify the engineering freshmen for the sake of retention. Otherwise they did not interact with an engineering faculty until their first physics course spring semester. Therefore, in Fall 1996 the first freshman engineering course was introduced at George Fox University, entitled Introduction to Computer Programming for Engineers. Such a course would also then be able to focus the programming assignments on engineering applications. In addition to structured programming techniques, the course began with an engineering design methodology component. 
Two team design experiences were included: a conceptual design project was completed by mid term, and a modular programming project by the end of the semester.

In Fall 2000 a new engineering major with electrical and mechanical concentrations was initiated at George Fox University, and with it a new freshman experience was developed entitled Engineering Principles I \& II. The new course incorporated the computer programming course and a separate engineering graphics course. The latter was previously taken at the sophomore or junior level and had not yet utilized computer aided engineering tools. The new course was to be much more than simply a training venue for programming and graphics, however, as this paper will show.

The new two-course Engineering Principles sequence is structured around two broad goals:

1. To expose the freshman engineering student to the work of engineering through handson activities and projects in engineering problem solving and design.

2. To train and equip the student in the application of the basic and essential skills and tools utilized in the engineering problem solving and design process.

The course provides an introduction to the concepts and methods of engineering problem solving and design, and covers the following topics: analysis and design methodologies, computer programming, engineering graphics and solids modeling, the visualization and modeling of realworld systems, and an introduction to the history and ethics of the engineering profession. The course also provides training for computer aided design tools, solid modeling and simulation software, and mathematics software applications, with immediate applications made in the context of actual engineering design problems. Electrical and mechanical (machining) laboratory experiences are also in the process of being incorporated into the course. The following are the course objectives:

1. To learn and apply the processes, methodologies, and skills useful in engineering design.

2. To gain experience in and become skilled in the engineering problem solving process.

3. To become proficient in the various analyses often utilized in the engineering design process (e.g. cost analysis and graphical analysis in Excel).

4. To acquire a foundational understanding of engineering graphics and become proficient in the use of SolidWorks solids modeling software.

5. To become proficient in structured programming techniques, through the use of the MATLAB programming environment.

6. To become familiar with the mathematical and graphical tools of MATLAB.

7. To gain experience and become proficient in basic machining skills and safety.

8. To gain experience and become proficient in basic electronic laboratory instrumentation and safety.

9. To introduce the basic theories of ethics and their application to the engineering profession.

10. To experience multidisciplinary teamwork in doing engineering design.

11. To gain experience in the various forms of engineering communication (memo-style progress reports, written final reports, poster presentations, and oral presentations) 
Though the subject matter is somewhat traditional, we have introduced innovative ways of structuring the class and engaging the first-year engineering students. In this paper we will present the various engineering design skills and tools integrated into the course, the projects based content of the course, the course structure, and an assessment of the objectives and the fulfillment of the engineering program outcomes.

\section{Course Focus: Engineering Design}

The two-course Engineering Principles sequence is focused on the topic of engineering design. The spirit, purpose, and content of the course are well represented by Mark Horenstein in his textbook Design Concepts for Engineers ${ }^{1}$ :

"...the notion of design in the context of engineering implies the application of knowledge and specialized skills toward the creation of something that meets a desired set of specifications. In an engineering context, the word "design" answers the simple question, "What do engineers do?" (p. 22)

Perhaps the most fundamental goal of this introductory course is to get students excited about engineering by getting them hooked on design. Therefore, from day one the students are doing engineering design. This is accomplished through individual homework, in-class design problems done in small groups, and team design projects. Historically, design courses have often been found much later in the engineering curriculum, after the student has completed the necessary foundational courses in mathematics, physics, and the engineering sciences. Our aim however, was to expose (and excite!) these future engineers much earlier to the work of engineering design by giving them a limited, yet significant, experience in actual design projects.

\section{An Integrative Approach: Design Skills}

A major benefit of the course's emphasis on engineering design is the ideal forum it provides for the introduction of many important design skills and tools. The context of solving actual engineering design problems serves as a highly effective avenue for the integration of vital engineering skills. 


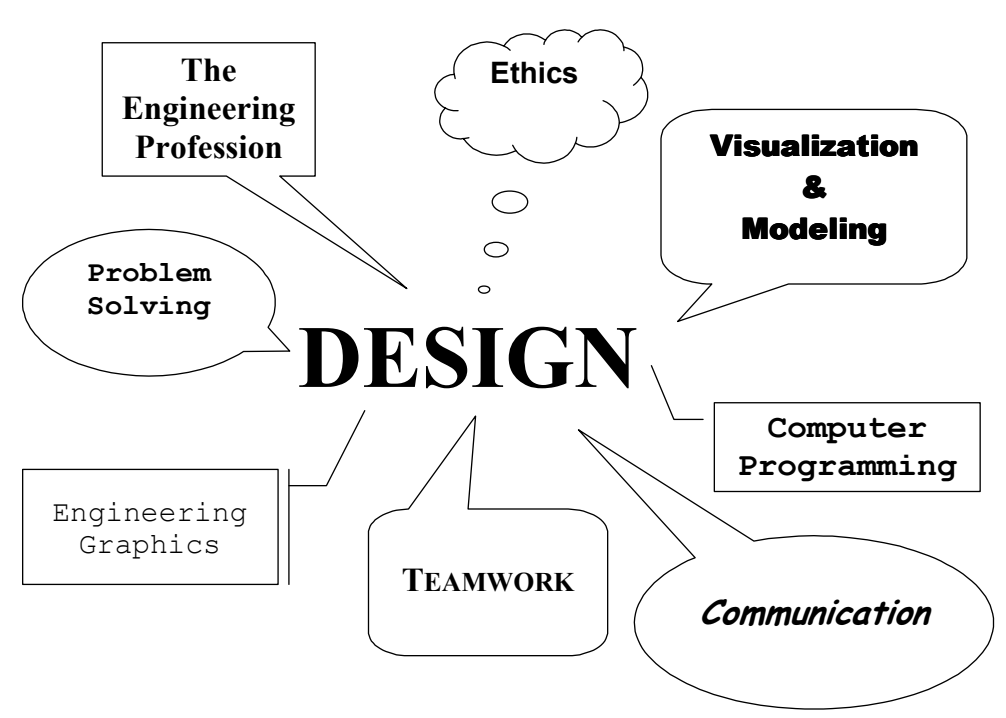

Fig. 1. A design-centered course.

Thus, in parallel to the course purpose of exposing students to actual engineering design projects is the synchronous objective of instructing and equipping the students in the use of several design skills and tools vital to the engineering process. Accordingly, course lectures and labs are used for instruction and experience in the applicable design skills and tools such as data/graphical analysis (spreadsheets), engineering graphics (solids modeling), computer programming and simulation (MATLAB), basic machining skills (building prototypes), and electronic laboratory skills. A comprehensive listing and description of the targeted skills is outlined below:

- Spreadsheet Skills (Excel) — The students are introduced to the basic spreadsheet software operations useful to the engineering design process, including methods for data presentation and analysis (tabular and graphical), calculations for mathematical functions, statistical operations, and cost analysis.

- Graphical Analysis - The graphical analysis tools of Excel and MATLAB are utilized to aid in design. The students learn to enter data directly or program generating equations to create the graphs. By adjusting parameters they can quickly interpret the changes to max and min values, intercepts and trends, etc. to complete the design problem at hand. The skills learned are also applicable to their upcoming lab courses in physics and engineering. For example, one assignment involves using Excel or MATLAB to model a projectile's path as a function of the initial parameters of launch velocity and angle, and analyzing and manipulating the graph(s) to achieve specified path conditions.

- Computer Programming — The programming language of MATLAB is used to introduce the students to high level, structured programming techniques. They learn control structures, file $\mathrm{I} / \mathrm{O}$, and function files. A design methodology is presented, which includes writing pseudocode with some flowcharting. MATLAB not only provides a very efficient means of teaching programming, but is chosen for its many intrinsic functions and toolboxes that are used in later courses.

- Solid Modeling - After a brief overview and training in freehand sketching, the students are trained in the basic skills of solids modeling through the SolidWorks software program. Regular homework assignments require the students to become proficient in all 
of the primary features of the program, applying them in the construction of a variety of parts, assemblies, and drawings.

- Visualization and Simulation - Both SolidWorks and MATLAB are tremendous tools for visualization. The solid modeling environment of SolidWorks gives the student an immediate picture of the object being designed. The $2 \mathrm{D}$ and $3 \mathrm{D}$ color graphing capabilities of MATLAB not only provide analysis but also visual effects that one cannot see in the numerical output directly. Furthermore, both SolidWorks and MATLAB also provide excellent simulation of programmed systems through their movie and animation tools.

- Teamwork / Project Management - Students are introduced to principles of team dynamics in lectures and subsequently required to practically apply the concepts in the context of the design projects which are carried out in teams of three to five students. The students are also instructed in the use of some basic tools utilized in project management such as company (team) organizational charts and Gantt charts.

- Basic Machining Skills - As a component of the course, all students are trained in the basic use of the bandsaw, drill press, milling machine, and lathe (completion of the training is required to pass the course). The final stage of the training requires the students' successful fabrication of an operating Wobbler steam engine ${ }^{2}$.

- Prototyping - Through the recent addition of a 3D plotter to our engineering lab facilities, the students have the opportunity to supplement their virtual solid model designs with an actual prototype of the relevant components (parts/assemblies). While such prototypes are obviously limited in their application to actual testing and implementation (primarily plaster models), they are indeed very useful in the design process, providing the students with opportunity to perform some limited analysis concerning the design's functionality.

- Electronics Measurement and Testing - This aspect of the freshmen experience will be implemented for the first time in Spring 2005. The current plan is to introduce the students to basic measurement techniques for voltage, current, and resistance using digital multimeters and digital oscilloscopes. The training for breadboarding will enable them to construct simple circuits and test for continuity and operation. An exciting project will be included for which the students will learn to solder components to a circuit board, such as a small microprocessor controlled, line-following car. This experience will give the students the skills to progress more rapidly in their sophomore electrical engineering laboratory experiments.

It is interesting to note the evolution of the design skills incorporated with the course, in conjunction with the development of the new major and new facilities. Table 1 provides a chronological overview of this process. Variations are expected over time, as the demands on this freshman course by upperdivision courses will change. 
Table 1. Chronology of course development and design skills.

\begin{tabular}{|c|c|c|c|c|c|c|c|c|c|}
\hline & $\begin{array}{c}\text { Computer } \\
\text { Programming }\end{array}$ & $\begin{array}{c}\text { Solid } \\
\text { Modeling }\end{array}$ & Teamwork & $\begin{array}{c}\text { Spread } \\
\text { Sheet }\end{array}$ & $\begin{array}{c}\text { Graphical } \\
\text { Analysis }\end{array}$ & Visualization & Machining & $\begin{array}{c}\text { Electronics } \\
\text { Measurement }\end{array}$ & Prototyping \\
\hline 1996 & $\mathrm{X}$ & & $\mathrm{X}$ & & & & & & \\
\hline 1997 & $\mathrm{X}$ & & $\mathrm{X}$ & & & & & & \\
\hline 1998 & $\mathrm{X}$ & & $\mathrm{X}$ & & $\mathrm{X}$ & & & & \\
\hline 1999 & $\mathrm{X}$ & & $\mathrm{X}$ & $\mathrm{X}$ & $\mathrm{X}$ & & & & \\
\hline 2000 & $\mathrm{X}$ & $\mathrm{X}$ & $\mathrm{X}$ & $\mathrm{X}$ & $\mathrm{X}$ & $\mathrm{X}$ & & & \\
\hline 2001 & $\mathrm{X}$ & $\mathrm{X}$ & $\mathrm{X}$ & $\mathrm{X}$ & $\mathrm{X}$ & $\mathrm{X}$ & & & \\
\hline 2002 & $\mathrm{X}$ & $\mathrm{X}$ & $\mathrm{X}$ & $\mathrm{X}$ & $\mathrm{X}$ & $\mathrm{X}$ & & & \\
\hline 2003 & $\mathrm{X}$ & $\mathrm{X}$ & $\mathrm{X}$ & $\mathrm{X}$ & $\mathrm{X}$ & $\mathrm{X}$ & & & \\
\hline 2004 & $\mathrm{X}$ & $\mathrm{X}$ & $\mathrm{X}$ & $\mathrm{X}$ & $\mathrm{X}$ & $\mathrm{X}$ & $\mathrm{X}$ & $\mathrm{Y}$ & \\
\hline
\end{tabular}

$\mathrm{X}=$ Implemented.

$\mathrm{Y}=$ Limited implementation with further implementation planned.

\section{Active learning: A Projects-Based Environment}

In an effort to allow the students to not only learn theoretically about the engineer's work of design, but to actively engage in this work, the students work on five major design projects during the year (in teams ranging from three to five members). These begin with a conceptual design project emphasizing the design process and methodology itself, followed by a reverse engineering project complete with a solid model design and actual prototype using a 3D plotter, $\underline{\text { a }}$ "Wobbler" steam engine project involving the design and actual manufacturing/machining of a working engine $^{2}$, a design by computer simulation, and finally the computer control of a realworld device (robotic arm). Students are required to communicate their results through oral and written reports, which take a variety of forms depending on the project: giving demos, PowerPoint presentations, formal reports, posters, and/or engineering proposals. It is in the specific context of these projects that the students are introduced to the necessary engineering design tools, and instructed in the appropriate application of the tools to complete their design project. The five major team design projects are outlined below.

\section{Conceptual Design}

After only a few sessions of lecture on the fundamentals and main principles of engineering design, the students are assigned their initial design project. The goal of the first project is to expose the students to the stages of the "design cycle" through their own application of each stage in an actual conceptual design problem. Student teams are required to work through the five steps of (1) Problem definition, (2) Gathering information, (3) Generation of multiple solutions, (4) Analysis and selection of solution, and (5) Testing and implementation of solution ${ }^{3}$. Upon completion, each team is required to submit a written report containing a thorough description of their activities in each of the five steps, and the final solution that resulted. Special emphasis is placed on the design process over the final solution (a great difficulty for these young and eager engineers!). An oral presentation to the class of their report is also required. A recent idea, for implementation in the next sequence, is to use the videotaped presentations for critique and class instruction in more effective communication.

With the focus on successfully working through the design cycle steps (more than the solution), virtually any hypothetical engineering problem can be assigned. Of course, a 
"good" problem is more conducive to a good learning experience. Recent conceptual design problems assigned include: a projectile launcher (with given performance specifications), a ceiling-mounted rack for televisions, a bicycle rack for pickup truck beds, a car console holder for cell phones ${ }^{3}$.

\section{$\underline{\text { Reverse Engineering }}$}

By the midpoint of the first semester, the students are very familiar with the basics of design methodology and have completed one full "cycle" with their conceptual design project. New student teams are formed and the teams are again required to work through the design cycle stages - this time however, in the context of the reverse engineering of an existing product. The teams are instructed to identify and purchase a product $(\$ 15$ budget) which they are then required to first dissect, and thereby gain a thorough understanding of how it works. Subsequently, they are given the goal of identifying one particular aspect of the product's function that they will "improve" through redesign. The specific product and improvement goal must be presented to the professor and accepted as a viable project (often the professor will consult with the teams to guide them to a more feasible and acceptable goal). Upon acceptance of the project, the teams begin their design with an appropriate problem definition and carry out the design steps in an attempt to achieve the defined objectives.

Upon completion, the teams are required to create and submit a poster presentation. The poster requirements are two-fold: (1) to effectively communicate exactly how the product works, and (2) to effectively identify and explain the redesign objectives. For obvious reasons, the latter component is typically limited to a conceptual redesign, with the teams carrying the design process up to, but not into, the testing and implementation stage. As a minimum, a complete virtual SolidWorks model is required for the redesigned product or part, and teams are encouraged, whenever possible, to print a 3D model of their redesign and perform whatever form and function analysis possible. All of the posters are presented for the entire campus community to view at the semester-end "Freshman Engineers Celebration," in conjunction with the Wobbler project demonstrations.

Again, there are an unlimited number of potential product redesign objectives that could be undertaken for this design project. Some recent ideas include: the redesign of a rotating sprinkler for increased angular velocity, the redesign of a shopping cart (wheel) for improved turning, and the redesign of a rollerblade skate for better stability.

\section{$\underline{\text { Wobbler Steam Engine }}^{2}$}

This is the third and final project of the first semester. After a brief introduction to the form and function of a Wobbler steam engine, the students are given the assignment to design and machine a small steam engine. Students worked in pairs, dividing the parts and creating an operating engine together.

Spreadsheet skills are applied in the design of the engine, both as a functional analysis tool, and as a cost analysis tool. Subsequently, the students are required to create solid 
models of all the parts and a finished working virtual assembly of their engine in SolidWorks (complete with detailed drawings). Finally, the students undertake the task of machining their respective parts, and creating a running engine. All of the engines are demonstrated for the entire campus community to view at the semester-end "Freshman Engineers Celebration," in conjunction with the reverse engineering project posters.

\section{Computer Simulation}

The computer simulation project is the first major project that the students code in MATLAB. They are divided into teams of three to four and given a significant program to write that simulates a real-world system. Each team takes the role of a consulting company being called on to complete the given project. The program is to be written in modular form, thus facilitating the group effort by requiring each of them to write individual parts of the code that must then work together cohesively. The function file format of MATLAB is introduced right before the project is assigned in a just-in-time approach, such that they are learning function file applications while doing the project. The students are given a complete problem statement with specifications, design criteria, and report requirements. An optimization of the code is expected.

The most recent project has been the simulation of radio waves radiating from three antennas in a room for the purpose of motion detection. The goal is to do a power calculation that ensures the most even distribution of energy in the room at a specified level while keeping the antenna feed currents to a minimum. The students are given the operating equations, which include complex numbers, but need to develop the convergence routine completely on their own. They utilize the 3D plotting routines of MATLAB to visualize their results and verify their design. Because the project is much more significant than any program they've written for the course, they're given a recommended design procedure. It outlines the six MATLAB functions they'll have to code and the expected output of the program, including tabulated data and color 3D plots. They're shown similar examples in class of radiating systems with a complete demonstration in MATLAB.

An additional feature that was added last year was an animation of the waves traveling throughout the room using the movie features of MATLAB; this was submitted as an AVI file along with the report. This was especially beneficial in that the students were able to see the system in action.

\section{$\underline{\text { Robotic Arm Control }}$}

The Robotic Arm Control project is the final one of the year. It allows the students to interact with a real-world electromechanical device. At a very fundamental level, it includes elements of robotics, real-time control, machine vision, artificial intelligence, and instrumentation. In teams of three to four, the students are working with a small robotic arm with four degrees of motion and a gripping device as the hand. They need to design a program that will control the arm to get it to perform a given function. For example, this past year's problem statement was as follows: 
Using a MATLAB program, automatically guide a robotic arm to find a small cylinder $(\mathrm{H} 10 \mathrm{~cm} \times \mathrm{D} 2.7 \mathrm{~cm})$ located in a designated work area, pick it up, and deposit it in a nearby receptacle. On placing the cylinder in the receptacle, the arm returns to its start position, completing the task in the shortest amount of time. This function is to be accomplished in solo as well as in competition with one other arm.

(A diagram was included in the handout to show the specific locations.) The process is completely autonomous, that is, no human input can be provided. They have four sets of infrared transmitters/detectors to attach to the arm that can be arranged as photogates or photoreflectors, allowing the arm to see the object and move it to the desired location. The interface board is provided, which communicates with MATLAB via the parallel port. From MATLAB they are receiving bits to read the sensors and sending bits to control the five drive motors. They are given a demonstration in class and handouts on the operation of the sensors and basic instructions from MATLAB to control the arm.

The programming is done in a modular format, to facilitate the team effort as well as teach the need for problem decomposition. It is up to the teams to divide the labor among themselves. They are also given a written design strategy, to show them a logical process they can follow: first testing the limitations of the arm and sensors, then using the manual controls to walk the arm through the necessary sequence, developing a pseudocode and flowchart, and testing each module of the program independently; finally, implementing and testing the complete program and optimizing their code. The teams are also encouraged to be creative and go beyond the minimum requirements.

A written report is required, which must include a one-page review of how robotic arms are currently used in industry, along with a solid model of the arm done in SolidWorks, showing the location and function of the infrared sensors. One class period is designated for the demonstrations, filled with much anticipation as the teams cheer each other's arms to success. The project admittedly is approached by most with not a little intimidation, but what seems at first to be impossible has almost always ended in success. A very realistic experience for the students - to overcome the complete unknown. Now that we have added the capability of machining and electronic testing and measurement, future projects may require enhancements to the arm itself and the interface board.

These five projects provide the ideal setting in which the students can develop the targeted design skills. Table 2 shows how the design skills are incorporated into the various projects. 
Table 2. Assessment of design projects and design skills.

\begin{tabular}{|c|c|c|c|c|c|c|c|c|c|}
\hline & $\begin{array}{c}\text { Computer } \\
\text { Programming }\end{array}$ & $\begin{array}{c}\text { Solid } \\
\text { Modeling } \\
\end{array}$ & Teamwork & $\begin{array}{c}\text { Spread } \\
\text { Sheet }\end{array}$ & $\begin{array}{c}\text { Graphical } \\
\text { Analysis }\end{array}$ & Visualization & Machining & $\begin{array}{c}\text { Electronics } \\
\text { Measurement } \\
\end{array}$ & Prototyping \\
\hline Conceptual & & & $X$ & X & & & & & \\
\hline $\begin{array}{c}\text { Reverse } \\
\text { Engineering }\end{array}$ & & $\mathrm{X}$ & $X$ & $\mathrm{X}$ & $\mathrm{X}$ & $\mathrm{X}$ & $\mathrm{Y}$ & & Y \\
\hline $\begin{array}{c}\text { The } \\
\text { Wobbler }\end{array}$ & & $\mathrm{X}$ & $X$ & $\mathrm{X}$ & $X$ & $X$ & $X$ & & X \\
\hline $\begin{array}{l}\text { Computer } \\
\text { Simulation }\end{array}$ & $\mathrm{X}$ & & $\mathrm{X}$ & & $\mathrm{X}$ & $\mathrm{X}$ & & & \\
\hline $\begin{array}{c}\text { Robotic } \\
\text { Arm }\end{array}$ & $X$ & $X$ & $X$ & & & $\mathrm{X}$ & $\mathrm{Y}$ & $\mathrm{Y}$ & Y \\
\hline
\end{tabular}

$\mathrm{X}=$ Implemented.

$\mathrm{Y}=$ Future implementation planned.

\section{Course Structure}

The course is two credit hours each semester, though the students meet twice weekly in a lecture/lab setting for a total of three hours per week. This allows for the full range of teaching techniques, from traditional lecture times to active learning sessions to experimental work to group activities. It especially allows for that crucial contact time with the faculty to benefit retention. The aforementioned topics are presented within four main subjects: Design ${ }^{1}$, Engineering Graphics and Solid Modeling ${ }^{4}$, Computer Programming, and Engineering Ethics ${ }^{6}$. These are taught in a modular format, to allow for different sequencing to fit faculty loads. The two-course sequence is taught by two faculty, one mechanical engineering and one electrical. The following is a summary of the various pedagogical methods implemented for the course:

- Traditional Lecture-Portions of the lecture time are delivered in a traditional format each week, with the faculty presenting the material via the whiteboard or overhead projector and the students involved with taking notes.

- Active learning-The traditional lecture times are supplemented with numerous active learning experiences. This may take the form of group discussions and problem solving, exchanging results between groups and working off of each other's ideas, proposing solutions to a design statement, or preparing for debates on ethical issues.

- In-class assignments - Given the extended time period beyond the typical two hours, some class time is dedicated to the completion of assignments by the students, individually or in groups.

- Demonstrations - The faculty use a computer projection system to demonstrate the use of Excel, SolidWorks, and MATLAB to the class. By posing the right questions to the class, this can become a very interactive time with them.

- Laboratory experience-The lab times are limited to 20 students each. The primary purpose is for time dedicated to working on the software applications, with the instructor and student assistant working with the students as needed. These times also serve other purposes, whether it's a few minutes of additional lecture, further demonstrations, group time for projects, or time dedicated to the shop and electronics training.

- Industry exposure-Engineers from industry are invited to give guest lectures several times during the year. They are able to give the students insight on how engineering design is done on the job. 
- Presentations - The students are given ample opportunity to present their work in class, be it on one of the major design projects or an in-class assignment just completed, either in teams or individually. They learn from each other as they observe and critique.

- Hands-on training-As described above, a machine shop and electronics training is now part of the course.

\section{Relationship of Course to Engineering Program Outcomes}

The following is an assessment of the twelve program outcomes for Engineering Principles I \& II, as required by ABET Criterion $3(a-k)$. The program outcomes are written to reflect the mission and objectives of George Fox University, a faith-based educational institution that is anchored in the liberal arts tradition. It is noteworthy that this freshman course covers all but one of the outcomes, more than any other engineering course we offer.

a. an ability to apply knowledge of mathematics, science, and the engineering sciences for effective engineering problem solving-Problem solving techniques rely on an understanding of algebra, trigonometry, and basic science.

b. an ability to design and conduct experiments, as well as to analyze and interpret data to extract meaning-NA

c. an ability to design a system, component, or process to meet desired needs-Students complete numerous design problems throughout the semester. The two-course sequence includes four major team design projects, which are based on established problem definitions and performance criteria. The process includes theoretical and computer modeling, animation, and the prototyping/programming and testing of the final design.

d. an ability to serve on multi-disciplinary teams-Numerous in-class assignments require the students to work in groups. The students are assigned to interdisciplinary teams for the major design projects. Debate teams are formed to deliberate on various ethical case studies.

e. an ability to identify, formulate, and solve engineering problems using fundamental principles - Systematic problem solving skills are applied to each chapter's homework assignments. Computational logic is taught and applied. Solutions to design problems are tested and implemented.

f. an understanding of professional and ethical responsibility from a Christian worldviewProfessional responsibilities are presented and discussed. Ethical case studies are analyzed.

g. an ability to communicate truthfully and effectively-Many opportunities arise through the numerous group assignments for the students to develop their listening and speaking skills. The design projects required written reports, posters, and/or oral presentations. The ethics section of the course involves class discussions and debates.

$\mathrm{h}$. the broad education necessary to understand the impact of engineering solutions in a global and social context including an understanding of Christian stewardship of resources-Professional codes of ethics are presented and discussed. Christian stewardship of resources is discussed in the context of the design process.

i. a recognition of the need for, and an ability to engage in life-long learning-Although SolidWorks and the MATLAB programming language are exclusively taught and applied, the students are reminded and encouraged to expose themselves to as many computer 
tools and languages as possible, given the uncertain lifetime and application of any one application.

j. a knowledge of contemporary issues and an ability to interpret from a Christian worldview - The design component of the course incorporates the need for economical considerations. The ethics component incorporates political and cultural issues of the engineering workplace. A Christian worldview is included when addressing these issues.

$\mathrm{k}$. an ability to use the techniques, skills, and modern engineering tools necessary for engineering practice to develop responsible technologies-Analysis methods using Excel are taught with direct application to assigned homework and design projects. Students are thoroughly trained in the use of SolidWorks solid modeling software. The computer application MATLAB is used extensively for the analysis and synthesis of a wide variety of engineering problems. Its built-in plotting functions enable the graphical communication of results. The students process data files through their computer programs.

An additional program outcome was added to our criteria:

1. an exposure to the industry and engineering practice-Students are introduced to and encouraged to join the electrical and mechanical engineering professional societies. The design projects expose the students to mechanical devices, wireless systems, and robotic controls. In-class presentations from practicing engineers and on-site visits to engineering workplaces/jobsites are used to expose students to engineering practice.

The one outcome that the course does not include at this time is $b$, though it is likely that it will include it in the near future, to expose the students to some basic analysis of data collected directly from laboratory equipment that they will use in future engineering courses. Covering all of the program outcomes is certainly not the goal of the course, but is indicative of its breadth of content and delivery. The students are well equipped to carry on with the remainder of the program.

\section{Future Course Development}

Given the course's relatively young age, we are looking forward to further development of this freshman engineering sequence. Some primary issues to consider include:

- Load implications for faculty - volume of time and energy required to oversee the large quantity of student design projects contained in the course.

- Increasing facility and equipment requirements related to the course's laboratory and projects-based emphasis.

- Research of new (and refinement of existing) design projects to maximize integration of design methodologies and skills component of course.

- Balancing the tension between breadth of the content covered (design methodologies and skills) and depth of experience in actually doing engineering design. 


\section{Conclusions}

The projects-based focus of the course provides a highly effective venue in which the students can learn and practice the engineering problem-solving and design methodologies and skills introduced in the course. Furthermore, it fills an often-missed vital component of the freshman engineering experience by providing an exciting and fun look into the actual work of engineering.

An assessment tool for the Engineering Principles two-course sequence is currently underway. The first part, to be completed in spring semester 2005, will assess a) the added value of the new shop and electronics training, and b) the impact of the course on the students' decisions to stay in the engineering major. These will be accomplished by student surveys. Then in the next academic year, the second part will include assessment of a) the freshman to sophomore year retention, b) the fall to spring retention within the freshman year, c) the improvement on the performance in the sophomore electrical labs due to the electronics training, and d) the impact of the specific skills learned on the performance in the sophomore engineering courses. Both the students and faculty of sophomore courses will be included in these evaluations. In the years that follow, the plan is then to assess the effectiveness of the freshman course on preparing the students for their upperdivision coursework, especially for the yearlong senior design project.

The anecdotal evidence is very encouraging. The typical retention from the freshman to sophomore year was between $50-65 \%$, but the average is now definitely increasing. The initial course evaluations and observations are also very encouraging. The students show an obvious enthusiasm for the hands-on engineering design projects. Congruently, there is a noticeable strength in the students' understanding of and proficiency in the application of the various design skills and methodologies introduced in the course.

In summary, the course has been effective in attaining the overall course purpose of providing the students with a sample of real engineering that was both challenging and rigorous, and yet highly enjoyable - an experience effective in both equipping them and giving a vision of what lies ahead for them as engineers. We believe that the sentiment of the vast majority of the students is represented well by one student who said recently of his course experience, "I thoroughly enjoyed the course. This course gave us a real-life experience. We did not just learn about or watch engineers at work - we were engineers at work!"

\section{Acknowledgement}

We were introduced to the steam engine project at the 2004 ASEE conference through Joel Lenoir's paper, The Wobbler Steam Engine: A Connection Between the Past, Present, and Future of Mechanical Engineering ${ }^{2}$. It has proved to be the ideal complement to the course, giving the students the opportunity to carry a project beyond conceptual design and on to actual prototype fabrication and testing. The GFU engineering department is extremely thankful to Joel Lenoir for his creative project, and his invaluable help with the implementation of the Wobbler project at our institution. 


\section{Bibliography}

1. M. Horenstein, Design Concepts for Engineers, 2e, Prentice-Hall, 2003.

2. J. Lenoir, "The Wobbler Steam Engine: A Connection Between the Past, Present, and Future of Mechanical Engineering," Proc. 2004 ASEE Annual Conference and Exposition, Salt Lake City, Utah, June 20-23, 2004.

3. S. Howell, Engineering Design and Problem Solving, 2e, Prentice-Hall, 2002.

4. R. Lueptow and M. Minbiole, Graphics Concepts with SolidWorks, 2e, Prentice-Hall, 2003.

5. A. Gilat, MATLAB: An Introduction with Applications, Wiley, 2004.

6. C. Fleddermann, Engineering Ethics, 2e, Prentice-Hall, 2003.

JOHN NATZKE, PhD, started with George Fox University in 1995. His teaching responsibilities include microwave engineering, electromagnetics, analog electronics, communications, circuit analysis, computer programming and the freshman experience. His primary research interests include the analysis of antenna structures, microwave devices, and electromagnetic radiation phenomena using numerical methods.

NEAL NINTEMAN joined the faculty of George Fox University in 2000. In addition to teaching courses in engineering fundamentals, he teaches regularly in mathematics and general physics. 